\title{
Tibial fibrous dysplasia in children treated by llizarov technique - a review of treatment options
}

\author{
M.M. Bari, I. Shahidul, A. Tanvir, A.M. Shayan R. Bari \\ Bari-Ilizarov Orthopaedic Centre, Dhaka, Bangladesh
}

Fibrous dysplasia is a pathological condition, where normal medullary bone is replaced by fibrous tissue and small woven specules of bone. Fibrous dysplasia can occur in epiphysis, metaphysis or diaphysis. Occasionally, biopsy is necessary to establish the diagnosis. We present a review of operative treatment using the Ilizarov technique.

Keywords: fibrous dysplasia, tibia, deformity, children, Ilizarov apparatus

\section{INTRODUCTION}

The management of tibial fibrous dysplasia in children is curettage or subperiosteal resection to extra periosteal wide resection followed by bone transport. En bloc excision followed by distraction osteogenesis is our main treatment technique. In few cases, we did osteotomy at the true apex of the deformity and two smooth $1.5-\mathrm{mm} \mathrm{K}$-wires were introduced in the medullary cavity to maintain the axis and to prevent axis deviation. In this situation, the Ilizarov frame was applied with only biocompatible thin wires. In the same sitting, we can correct the deformity acutely. The potential advantage is to increase the bone regenerate $[1,2]$. We describe 18 cases of fibrous dysplasia in the tibia; 12 cases were treated by en bloc excision and bone transport, and 6 cases were treated by application of Ilizarov only with corrective osteotomy in the CORA and introducing two $1.5-\mathrm{mm}$ $\mathrm{K}$-wires in the medullary cavity.

\section{MATERIALS AND METHODS}

A total of 18 patients were treated between January 2010 and January 2020; 12 patients came with pain and 6 with pain and deformity. All patients were treated by the Ilizarov technique.

Age ranged from 4 to 14 years. 12 patients were managed by en bloc excision and bone transport, and 6 patients were treated by osteotomy at the true apex of the deformity and introducing the $\mathrm{K}$-wires in the medullary cavity with stable fixation with the Ilizarov device. The longest duration of bone transport was 16 weeks (14-20 weeks), and 20 weeks only with Ilizarov application after deformity correction. We never used any kind of bone grafts.

\section{RESULTS}

All the 18 patients were treated successfully with the Ilizarov compression-distraction device. The patients with localized tibial pathology with deformity had the shortest period with the Ilizarov apparatus on, 14 weeks.

\section{DISCUSSION}

There are varieties of treatment options in the literature, starting from casting, intramedullary nailing, plating and external fixation. Each has variable success rate and complications. The aim of this review was to show the outcomes of management with the Ilizarov device. This unique tool yields good outcomes and we are getting much less complications like wire-tract infection which can be managed by proper local dressing and application of antibiotics.

Fibrous dysplasiais caused by the sporadic mutation of the GNAS1 gene located on the chromosome of the osteoblastic cells [3]. Fibrous dysplasia may occur in any bone. Fibrous dysplasia presents clinically in children and adolescents, with a median onset age of 5 years. Monostotic fibrous dysplasia is active and becomes inactive after puberty [4]. Children seek medical care because of either painful swelling and deformity or a pathological fracture in a weakened bone. Radiographically, monostotic fibrous dysplasia includes a ground glass appearance with expansion of bone and sclerosis surrounding the lesion [5]. MRI does not provide characteristic appearance of fibrous dysplasia [6]. In our series, we used the Ilizarov techniques in two ways: 
a) We resected the whole tumor and then transported the bone fragment after application of stable Ilizarov apparatus;

b) At the true apex of the deformity, we did osteotomy and introduced $1.5-\mathrm{mm}$ guide wires to increase circulation in the medullary cavity.

We have not used the intralesion curettage and bone grafting. The Ilizarov technique has been well documented with good outcomes for treating fibrous dysplasia by applying load and motion which result in good healing in the pathologic area [2]. Compression favors to the formation of new bone between the bony surfaces. It gives neovascularization which actually simulates the new bone formation. In addition, there is histogenesis of muscles, nerves, skin. This new bone replaces pathological bone with normal bone. Due to its versatility, the Ilizarov apparatus allows 3-dimensional correction of deformity. The technique gives stability and creates mechanical force to induce new bone formation which is compatible to Ilizarov's law of tension stress [7]. The local blood supply and the integrity of the periosteum are well preserved by minimally invasive transosseous wires or when corticotomy is necessary [8]. When vascularity is preserved at fracture site, the bone will unite within the normal healing period [9]. And the greatest advantage after application of the Ilizarov apparatus is early weight-bearing. Weight-bearing is considered to be essential both for bone regeneration and consolidation.
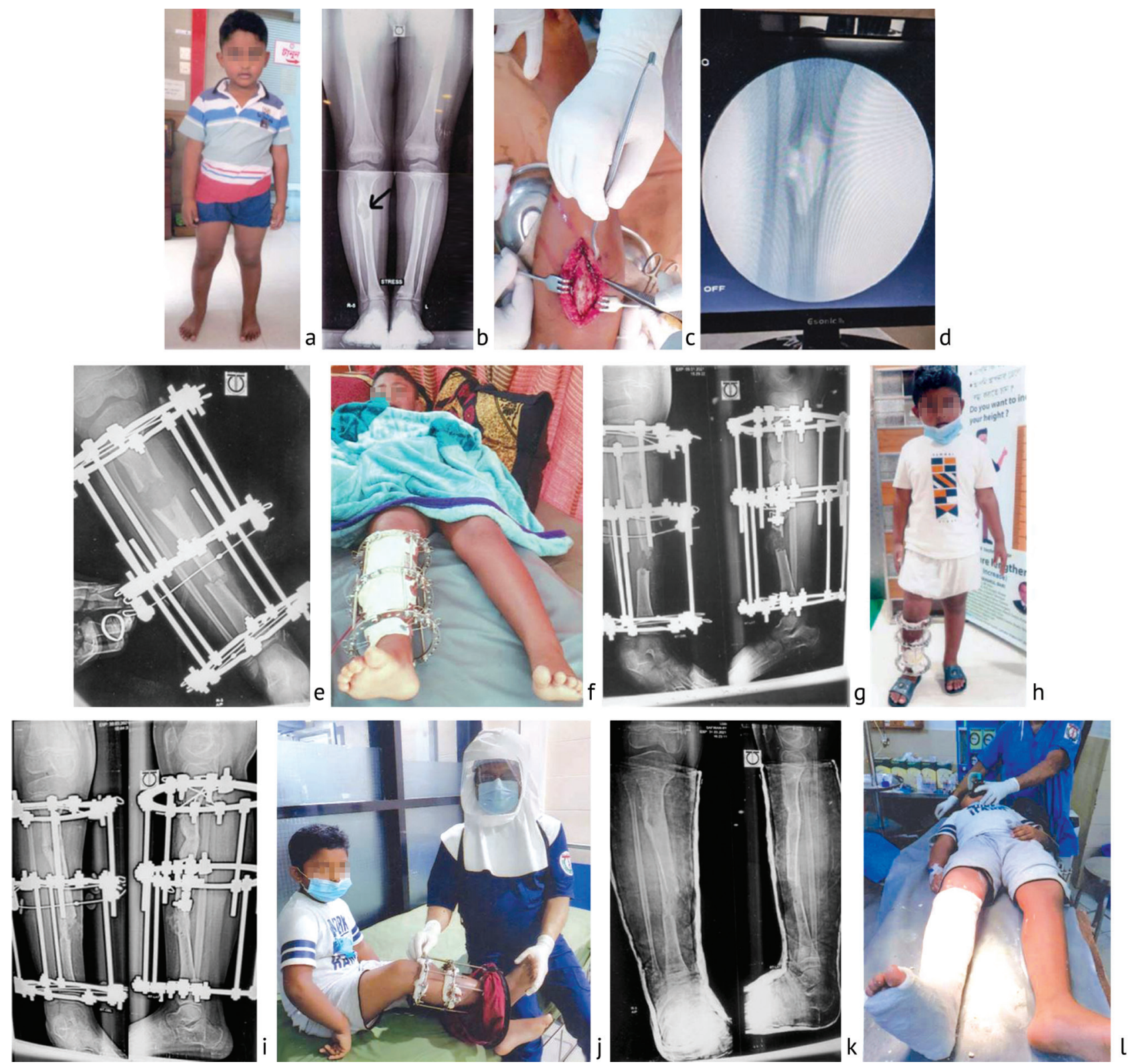

Fig. 1 6-year old boy; Histopathology report: GROSS: Bony fragments, total quantity about $5 \mathrm{ml}$. (All taken), MICRO: Tissue fragments showing feature suggestive of fibrous dysplasia: $\boldsymbol{a}$ clinical appearance of the patient before surgery; $\boldsymbol{b}$ radiographic view, right-sided fibrous dysplasia before surgery; $\boldsymbol{c}$ curettage and en bloc excision; $\boldsymbol{d}$ fluoroscopic view after curettage; $\boldsymbol{e}$ en bloc excision with Ilizarov application and corticotomy in the lower tibia; $\boldsymbol{f}$ patient with Ilizarov apparatus on; $\boldsymbol{g}$ radiographic view of bone transport; $\boldsymbol{h}$ standing position of the patient with Ilizarov apparatus; $\boldsymbol{i}$ radiographic view after 3 months and 15 days of bone transport and consolidation; $\boldsymbol{j}$ prof. M. M. Bari with the patient; $\boldsymbol{k}, \boldsymbol{l}$ after removal of Ilizarov apparatus, plaster immobilization 

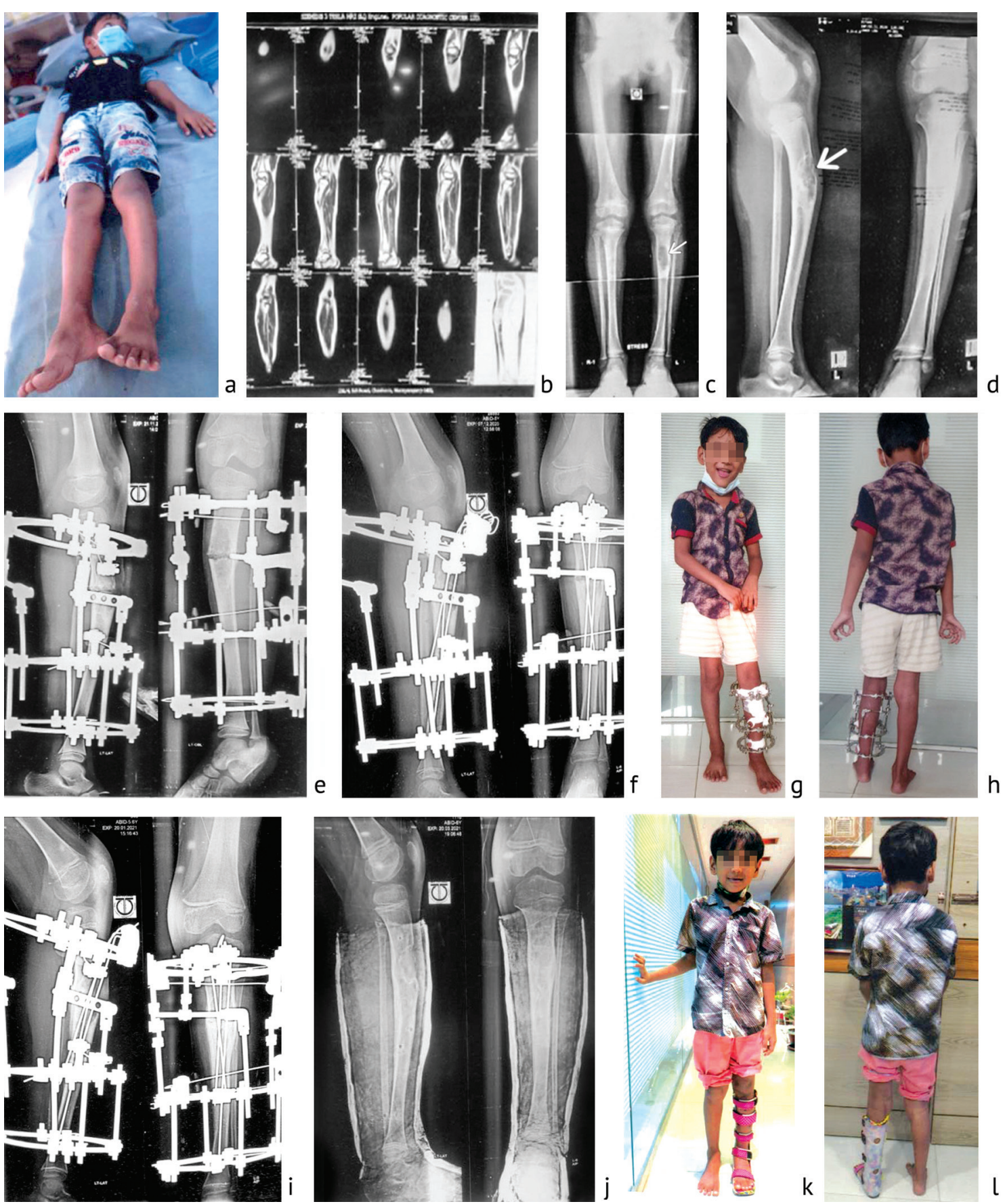

Fig. 2 5-year old boy; Histopathology report: Gross Description: Multiple places of soft and bony tissue fragments, soft tissue collectively measures $(10 \times 08 \times 06) \mathrm{mm}^{3}$ and bony tissue collectively measures $(8 \times 5 \times 2) \mathrm{mm}^{3}$. Sections code: 1$)$ all soft tissue embedded on one block, 2) all bony tissue embedded on one block. Microscopic Description: Sections from the submitted specimen reveal a lesion composed of Chinese figure-like trabeculae of woven bone within a proliferating fibroblastic stroma. Osteoblastic rimming of these trabeculae is seen. No granuloma or evidence of malignancy is seen. Histologic diagnosis: Tissue from tibia, left: Consistent with Fibrous Dysplasia: $\boldsymbol{a}$ clinical appearance of the patient before surgery; $\boldsymbol{b}$ CT scan of left tibia; $\boldsymbol{c}, \boldsymbol{d}$ radiographic view, left-sided fibrous dysplasia with procurvatum before surgery; $\boldsymbol{e}$ correction of the procurvatum deformity with simple osteotomy; $\boldsymbol{f}$ two 1.5 smooth K-wires introduced through the medullary cavity; $\boldsymbol{g}$, $\boldsymbol{h}$ smiling patient with the Ilizarov apparatus on ( front and back views); $\boldsymbol{i}$ before dismounting the Ilizarov apparatus after 3 months since the application of Ilizarov apparatus; $\boldsymbol{j}$ after removal of the Ilizarov apparatus, plaster immobilization; $\boldsymbol{k}, \boldsymbol{l}$ patient is on AFO (ankle foot orthosis)

Conflict of interest: All authors declare no conflict of interest.

Funding: There is no funding source.

\section{REFERENCES}

1. Ippolito E., Bray E.W., Corsi A., De Maio F., Exner U.G., Robey P.G., Grill F., Lala R., Massobrio M., Pinggera O., Riminucci M., Snela S., Zambakidis C., Bianco P.; European Pediatric Orthopaedic Society. Natural history and treatment of fibrous dysplasia of bone: a multicenter clinicopathologic study promoted by the European Pediatric Orthopaedic Society. J. Pediatr. Orthop. B, 2003, vol. 12, no. 3, pp. 155-177. DOI: 10.1097/01.bpb.0000064021.41829.94 
Genij Ortopedii, Vol. 27, no 3, 2021

2. Sakurakichi K., Tsuchiya H., Yamashiro T., Watanabe K., Matsubara H., Tomita K. Ilizarov technique for the correction of the Shepherd's crook deformity: a report of two cases. J. Orthop. Surg. (Hong Kong), 2008, vol. 16, no. 2, pp. $254-256$. DOI: $10.1177 / 230949900801600226$

3. DiCaprio M.R., Enneking W.F. Fibrous dysplasia. Pathophysiology, evalustion, and treat- ment. J. Bone Joint Surg. Am., 2005, vol. 87 , no. 8 , pp. 1848-1864. DOI: 10.2106/JBJS.D.02942

4. Lichtenstein L., Jaffe H.L. Fibrous dysplasia of bone: a condition affecting one, several or many bones, the graver cases of which may present abnormal pigmentation of skin, premature sexual development, hyperthyroidism or still other extraskeletal abnormalities. Arch. Pathol., 1942, vol. 33, pp. 777-816.

5. Singer F.R. Fibrous dysplasia of bone: the bone lesion unmasked. Am. J. Pathol., 1997, vol. 151, no. 6, pp. 1511-1515.

6. Chan B., Zacharin M. Pamidronate treatment of polyostotic fibrous dysplasia: failure to prevent expansion of dysplastic lesions during childhood. J. Pediatr. Endocrinol. Metab., 2006, vol. 19, no. 1, pp. 75-80. DOI: 10.1515/jpem.2006.19.1.75

7. Bari M.M. A color atlas technique of limb lengthening, surgical reconstruction and deformity correction by Ilizarov. Switzerland, Springer International Publishing, 2013, 139 p.

8. Bari M.M. Correction of leg deformities and restoration of function of leg bones by Ilizarov technique: A technical manual for orthopaedic surgeons. Ed. II. MedCrave, 2015, 164 p.

9. Tsuchiya H., Tomita K., Matsumoto T., Watanabe S. Shepherd's crook deformity with an intracapsular femoral neck fracture in fibrous dysplasia. Clin. Orthop. Relat. Res., 1995, no. 10, pp. 160-164.

Received: 19.04.2021

\section{Information about the authors:}

1. Mofakhkharul M. Bari, M.D., Ph.D, Professor,

Bari-Ilizarov Orthopaedic Centre, Dhaka, Bangladesh,

Visiting and Honored Professor, Russian Ilizarov Scientific Centre, Kurgan,

Email: bari.ilizarov31@gmail.com

2. Islam Shahidul, M.D., Ph.D, Professor,

FCPS, Bari-Ilizarov Orthopaedic Centre, Dhaka, Bangladesh

3. Ashraf Tanvir, M.D.,

NITOR

4. A.M. Shayan R. Bari, MS (Ortho),

Bari-Ilizarov Orthopaedic Centre, Dhaka, Bangladesh 